\title{
Proximal and distal predictors of self- regulatory change in children aged 4 to 7 years
}

Kate E. Williams ${ }^{1 *}$ (D) and Steven J. Howard ${ }^{2}$

\begin{abstract}
Background: Growth in early self-regulation skills has been linked to positive health, wellbeing, and achievement trajectories across the lifespan. While individual studies have documented specific influences on self-regulation competencies in early childhood, few have modelled a comprehensive range of predictors of self-regulation change across health, development, and environment simultaneously. This study aimed to examine the concurrent associations among a range of proximal and distal influences on change in children's self-regulation skills over 2 years from age $4-5$ years.

Methods: Data from the Longitudinal Study of Australian Children $(N=4983)$ were used in a structural equation model, predicting a multi-source composite measure of self-regulation at each of 4-5 years and 6-7 years. By controlling for earlier self-regulation and covariates, the model examined the relative contributions of a comprehensive range of variables to self-regulation change including health, development, educational, home environment, time-use, and neighbourhood characteristics.
\end{abstract}

Results: The significant predictors of children's self-regulation growth across 4 to 7 years were fewer behavioural sleep problems, higher gross motor and pre-academic skills, lower levels of maternal and paternal angry parenting, and lower levels of financial hardship. There were also marginal effects for high-quality home learning environments and child-educator relationships.

Conclusion: Findings suggest that if we are to successfully foster children's self-regulation skills, interventionists would do well to operate not only on children's current capacities but also key aspects of their surrounding context.

Keywords: Early childhood, Self-regulation, Self-control, Predictive model

\section{Background}

Self-regulation refers to the ability to exert control over our cognition, emotion, and behaviour in ways that are adaptive to functioning. These skills develop across the lifespan, but most rapidly in early childhood alongside cortical maturation processes. In terms of self-regulation development, early improvements appear to be better,

\footnotetext{
* Correspondence: k15.williams@qut.edu.au

${ }^{1}$ School of Early Childhood \& Inclusive Education, Faculty of Education, Queensland University of Technology, QUT, Level 4 E Block, Victoria Park Road, Kelvin Grove, QLD 4059, Australia

Full list of author information is available at the end of the article
}

with strong early childhood self-regulation skills linked with a wide range of health and achievement outcomes across the lifespan, including positive mental and physical health, and educational attainment [1-3]. In contrast, poorer selfregulation in early childhood has been linked with school adjustment difficulties [4], behaviour problems [5], adolescent risk-taking [2], and adult disordered behaviour [6].

Early childhood is a period in which growth in selfregulation is not only particularly desirable, but also demonstrably possible. In fact, growth in self-regulation skills in the early years of life (controlling for early self-

(c) The Author(s). 2020 Open Access This article is licensed under a Creative Commons Attribution 4.0 International License, which permits use, sharing, adaptation, distribution and reproduction in any medium or format, as long as you give appropriate credit to the original author(s) and the source, provide a link to the Creative Commons licence, and indicate if changes were made. The images or other third party material in this article are included in the article's Creative Commons licence, unless indicated otherwise in a credit line to the material. If material is not included in the article's Creative Commons licence and your intended use is not permitted by statutory regulation or exceeds the permitted use, you will need to obtain permission directly from the copyright holder. To view a copy of this licence, visit http://creativecommons.org/licenses/by/4.0/ The Creative Commons Public Domain Dedication waiver (http://creativecommons.org/publicdomain/zero/1.0/) applies to the data made available in this article, unless otherwise stated in a credit line to the data. 
regulatory levels and family environment) has been found to reduce risk of childhood behaviour problems [5], adolescent crime, self-harm, and mental health problems [2], as well as enhance academic learning trajectories [7]. Given limited understanding of antecedents of early selfregulation change that can shift trajectories and outcomes more broadly, intervention approaches remain incongruous. For instance, approaches to self-regulation intervention include computerized executive function training, specialized preschool curricula, physical activities, arts and music, motor skill development, and so forth [8-10]. While it is indeed likely that multiple approaches will be effective, and ideally suited to different contexts, needs and children, the design of interventions would nevertheless be improved through a more comprehensive and holistic understanding of early childhood factors and experiences that support self-regulation development.

The individual and environmental conditions that support optimal development in self-regulation across early childhood remain relatively unclear. Various lines of inquiry have identified longitudinal predictors associated with better point-in-time self-regulation in early childhood including rich home learning environments [11], positive parenting approaches [12], stronger motor [13] and language development [14], and well-adjusted sleep behaviours [15]. However, very few studies have examined the extent to which these, and other plausible proximal and distal factors predict change in self-regulation over time. The aim of this study is to investigate the concurrent associations among a range of proximal and distal influences on change in children's self-regulation skills over 2 years beginning at $4-5$ years of age.

\section{Methods}

\section{Participants}

This study used data from the population-representative Kindergarten (K) cohort of the Longitudinal Study of Australian Children (LSAC), with full study design details described elsewhere [16]. In brief, for the K cohort, 4983 children aged 4-5-years old were recruited in 2004 with biennial data collection occurring since then. Data collection involves parent and teacher questionnaires, computer assisted interviews with parents and children, and direct assessments with children. The current study uses data collected for the $\mathrm{K}$ cohort across two waves (when children were 4- to 5-years old and 6- to 7-years old). Table 1 describes the characteristics of the sample.

\section{Measures}

Self-regulation was assessed at 4-5 and 6-7 years of age using a factor score we have previously established as a reliable indicator of children's self-regulatory capacity with good predictive validity of broad later-life outcomes into adolescence [2]. A total of 20 survey items from parent-,
Table 1 Sample characteristics

\begin{tabular}{ll}
\hline Study sample characteristic & Percentage \\
\hline Boys & $51 \%$ \\
English as main home language & $86 \%$ \\
Aboriginal or Torres Strait Islander & $3.8 \%$ \\
Mothers with incomplete high school & $22 \%$ \\
education & \\
Mothers with university education & $28 \%$ \\
Attending preschool program at & $95 \%$ \\
4-5 years & \\
& M (SD) \\
Child age at 4-5 year data collection & 56.9 months (2.65) \\
Child age at 6-7 year data collection & 81.9 months (2.96) \\
Household income per week & \$1661.93AUD (\$1294.05) \\
\hline
\end{tabular}

teacher-, and observer-report ratings of self-regulation were standardized and then averaged to create a single composite score $(M=0, S D=1)$. Constituent items of this factor index the extent to which children can control and sustain their attention, and control their behaviour and emotions (see Table 2). Internal consistency was high (alpha $=0.84$ at $4-5$ years, 0.86 at $6-7$ years).

Predictors of self-regulation change were selected from the domains of health, development, home environment, education, time use, and neighbourhood measured when children were 4-5-years old. Details of each of these are provided in Table 3. Where parent-report is indicated, this was provided by Parent 1 (defined by LSAC as the parent who knows the study child best, which in $97 \%$ of cases was the mother).

Control variables included in the analyses were gender, age of assessment (in months) at baseline, birth weight percentile, whether or not the child had ever been breastfed, Aboriginal and Torres Strait Islander status, Non-English speaking home background, maternal education level (on a 6-point scale from incomplete high school to postgraduate degree), and household income bracket. We used data from the age 4-5 years data collection for these variables, providing the most complete data possible (before attrition in the longitudinal study).

\section{Approach to analysis and missing data}

A structural equation model was tested in Mplus version 7.11. Figure 1 depicts the model, showing self-regulation at 6-7 years predicted by the full range of variables described above, while controlling for self-regulation measured two years earlier. This approach to modelling means the estimates for the predictors represent their impact on residualized change in self-regulation from 4 to 7 years of age, because the effect of the earlier measure of self-regulation has already been accounted for. Additionally, effects of stable covariates present from birth on earlier self- 
Table 2 Items included in the self-regulation measure at 4-5 years and 6-7 years

\begin{tabular}{|c|c|c|}
\hline Construct & Respondent & Item \\
\hline \multirow[t]{3}{*}{ Impulsive Aggression } & Parent and teacher & Often has temper tantrums/hot tempers \\
\hline & Parent and teacher & Often fights with other children or bullies them \\
\hline & Parent and teacher & Often argumentative with adults \\
\hline \multirow[t]{3}{*}{ Hyperactivity } & Parent and teacher & Restless, overactive, cannot stay still for long \\
\hline & Parent and teacher & Constantly fidgeting or squirming \\
\hline & Parent and teacher & If this child is upset, it is hard to comfort him/her \\
\hline \multirow[t]{4}{*}{ Lack of Persistence \& Inattention } & Parent and teacher & $\begin{array}{l}\text { The child likes to complete one task or activity } \\
\text { before going on to the next (reversed) }\end{array}$ \\
\hline & Parent and teacher & $\begin{array}{l}\text { Sees takes through to the end, good attention } \\
\text { span (reversed) }\end{array}$ \\
\hline & Parent and teacher & $\begin{array}{l}\text { The child stays with an activity (e.g., puzzle, } \\
\text { construction, kit, reading) for a long time (reversed) }\end{array}$ \\
\hline & Parent, teacher, and observer & Easily distracted, concentration wanders \\
\hline \multirow[t]{3}{*}{ Impulsivity } & Parent and teacher & Can stop and think things out before acting (reversed) \\
\hline & Parent and teacher & Shares readily with other children (reversed) \\
\hline & Observer & $\begin{array}{l}\text { Degree of negative mood (withdrawn, uncooperative, } \\
\text { sulky, seeming upset, angry) to interview }\end{array}$ \\
\hline
\end{tabular}

regulation were controlled for. Correlations among all predictor variables were included in the model, with the strongest significant correlation as $\mathrm{r}=.45$ for the correlation among teacher-reported gross motor and fine motor skills. Due to the large sample size, we use a conservative $p$ value of $<.01$ to indicate a significant effect and $<.02$ for a marginally significant effect.

The amount of missing data varied across waves and variables, ranging from no missing data for sociodemographic characteristics at $4-5$ years to $45 \%$ missing data for the self-regulation scores at 4-5 and 6-7 years due primarily to item-level missing data from teacher non-report. The data were considered missing at random (MAR) because it was unlikely that the presence of a missing value was related to the response that would have been given [31]. We used full information maximum likelihood with a robust estimator to address missing data, allowing us to retain $98 \%$ of the sample in the statistical models. We used the sampling weights provided for LSAC [32] to account for sampling error.

\section{Results}

The model was a good fit for the data and accounted for $42 \%$ of variance in self-regulation at $6-7$ years, with all estimates shown in Table 4. Self-regulation skills at 6-7 years, after controlling for self-regulation skills at 4-5 years, were predicted by fewer behavioural sleep problems, higher gross motor and pre-academic skills, lower levels of maternal and paternal angry parenting, and lower levels of financial hardship. There were also marginal effects for the home learning environment and child-educator relationships. Covariates associated with stronger self-regulatory skills at 6-7 years including being a female, having a higher birthweight percentile, identifying as non-Aboriginal and Torres Strait Islander, having a mother with a higher level of education, and a higher household income.

\section{Discussion}

This is the first paper to model a comprehensive and concurrent set of predictors across health, development, and environment in relation to self-regulatory development of young children, across a two-year period beginning from age 4-5 years. Controlling for a range of background factors, significant predictors of self-regulatory growth included: fewer behavioural sleep problems; higher gross motor and pre-academic skills; lower levels of maternal and paternal angry parenting; lower levels of financial hardship; and marginal effects for home learning environment and child-educator relationships. As predictors were modelled simultaneously, significant findings provide a (likely conservative) estimate of the associations between each variable and self-regulation change, over and above the combined associations of all other variables in the model. While previous studies have provided insight into the transactional mechanisms between some factors known to influence self-regulation (e.g. parenting and sleep), this model better reflects the complexity of children's lives and the combined impact of a range of factors on self-regulatory change. Thus the study makes an important contribution toward prevention and intervention efforts by identifying the most salient and high-potential factors to target for self-regulation interventionists taking 
Table 3 Predictors of self-regulation growth in the model

\begin{tabular}{lll}
\hline Construct & Data source & Measure \\
\hline $\begin{array}{l}\text { Health \& Health Behaviours } \\
\text { Physical health }\end{array}$ & Parent & $\begin{array}{l}\text { Physical Health Summary score from the Pediatric Quality of Life Inventory (PedsQL) [17]. Summed } \\
\text { and average score of } 8 \text { items each rated on 5-point scale, tapping a child's level of functioning in } \\
\text { daily activities that rely on good physical health. E.g. problems with running. } a=.72 \\
\text { Units of high sugar drinks consumed in the last week }\end{array}$ \\
$\begin{array}{ll}\text { Diet quality } \\
\text { Behavioural sleep problems }\end{array}$ & Parent & $\begin{array}{l}\text { Five items modelled as a latent variable as per prior studies [18]. E.g. child has problems on } 4 \text { or } \\
\text { more nights a week with waking during the night (yes/no); this child's sleep is a small/moderate/ } \\
\text { large problem. }\end{array}$
\end{tabular}

\section{Development}

Receptive vocabulary

Gross motor development

Fine motor development

Pre-academic skills

Home environment

$\begin{array}{ll}\text { Maternal parenting anger } & \text { Mother } \\ \text { Paternal parenting anger } & \text { Father } \\ \text { Maternal parenting consistency } & \text { Mother } \\ \text { Paternal parenting consistency } & \text { Father } \\ \text { Maternal mental health } & \text { Mother } \\ \text { Paternal mental health } & \text { Father } \\ \text { Home learning environment } & \text { Parent }\end{array}$

Financial hardship

Argumentative parental relationships

Stressful life events

\section{Education}

Teacher-child relationship

Teacher

\section{Time use}

Extra-curricular sport

Extra-curricular music / dance

Weekday TV hours

Weekday computer hours

Physical activity

\section{Neighbourhood}

Liveability

Socio-economic index for area (SEIFA)

Assessed

Teacher

Assessed

Parent
Peabody Picture Vocabulary Test [19] of receptive vocabulary in which children listen to a spoken word and are asked to point to the matching picture given a set of four pictures. Higher scores represent higher receptive vocabulary skills.

Teacher On a 4-point scale from 'much less competent than peers' to 'more competent than peers'

On a 4-point scale from 'much less competent than peers' to 'more competent than peers'

Who Am I test [20]. Children write their names, copy shapes, write words and numbers; scored according to skill level. $a=.89$ [21]

Composite measure (weighted mean score) as per LSAC technical advice [22] using four adapted items from the National Longitudinal Study of Children \& Youth [23]. Each item rated on 5-point scale from 'never or almost never' to 'almost always'. E.g. how often are you angry when you punish this child? $\mathrm{H}=.72$.

Composite measure as per LSAC technical advice [22] using five items from the National Longitudinal Survey of Children and Youth [23]. Each item rates on a 10-point scale from 'not at all' to 'all of the time'. E.g. how often does this child get away with things that you feel should have been punished? $H=.80$ for father; .82 for mothers.

Kessler K6 screening scale [24] of six items (summed and averaged) about respondents' feelings over the past four-week period. Rates on 5-point scale from 'all of the time' to 'none of the time'. E.g. in the past 4 weeks how often have you felt hopeless? $a=.84$ for mothers, .82 for fathers.

Single item book reading; plus latent variable with five indicators of other home learning activities including music, art, and play as used in other LSAC studies [25]. Each rated on 4-point scale of frequency of adult-child engagement for each activity in the last week from 'not in the past week' to '6-7 days in the week'.

Parent $\quad$ 7-item count index ranging from 0 to 7, based on summing Yes $=1$, No $=0$ responses to 7 items including couldn't pay bills, gone without meals as used in prior LSAC research [26].

Composite of 5 items (summed and averaged) rated on a 5-point scale from 'never' to 'always'. E.g. my partner and I argue; disagree over child-rearing etc. $a=.80$

Parent 13-item count index ranging from 0 to 13 based on summing Yes $=1$, No $=0$ responses about exposure to adverse life events over the past year including marital breakdown, death of friend, as per prior LSAC research [27].

8-item composite drawn from the Student Teacher Relationship Scale [28] following prior LSAC factor modelling [29]. Each item rated on 5-point scale from 'definitely does not apply' to 'definitely applies'. E.g. share affectionate relationships, easy to be in tune with feelings $a=.81$

Sum of 3 items indicating participation (yes / no) in extra-curricular swimming, gymnastics, or team sport

Parent Sum of 2 items indicating participation (yes / no) in extra-curricular music and dance

Parent Number of hours watching TV on a typical weekday

Parent Number of hours using a computer on a typical weekday

Parent Parent-rated child enjoyment of physical activity on a 5-point scale from 'very much dislikes physical activities' to 'very much likes physical activity'

Parent Composite (sum) of 8 items each rated on 4-point scale from 'strongly disagree' to 'strongly agree'. E.g. this is a safe neighbourhood, this neighbourhood has good parks. $a=.76$

Australian Bureau Composite of 31 variables (e.g. income, unemployment, occupation and education) computed by of Statistics the Australian Bureau of Statistics [30] 


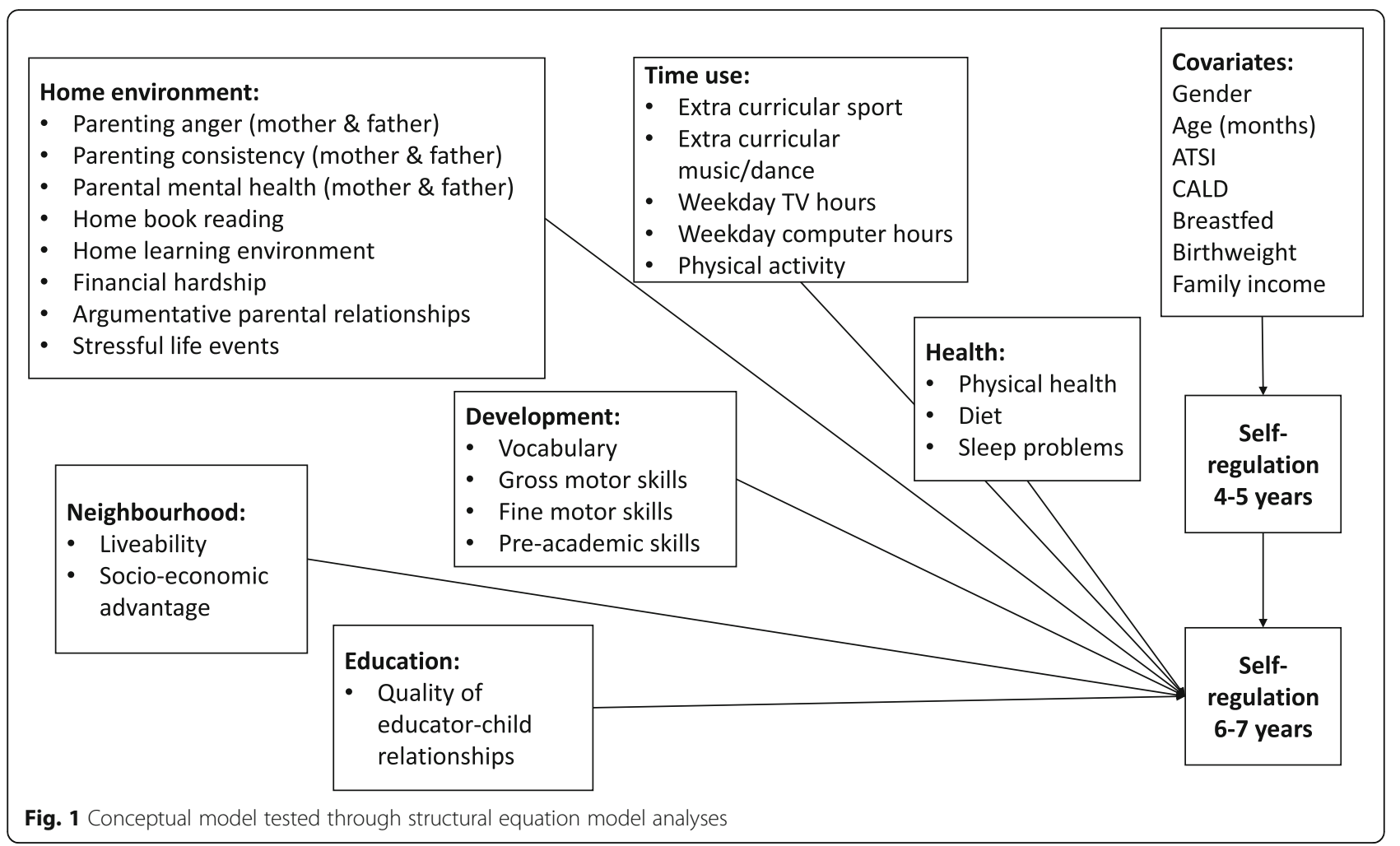

a holistic approach to supporting self-regulatory growth in young children.

Substantial research and theory supports both acute and persistent associations of self-regulation with learning and academic skills [33] with self-regulation typically positioned as a predictor of academic skills. In a related finding, but with self-regulation as the outcome, in our model pre-academic skills were one of the strongest predictors of self-regulation growth. It is clear why self-regulation would predict learning and academic skills: the ability to direct and sustain attention, tackle new challenges, resist maladaptive impulses, and work collaboratively and prosocially with others - all hallmarks of high self-regulation - serve to support on-task behaviour, effort and persistence during learning. However, there is comparatively less research focused on the possible reciprocal effects with pre-academic skills predicting self-regulation growth. A number of explanations are feasible. First, it is likely that self-regulation and early literacy and numeracy skills, as represented by our pre-academic skill assessment, develop in a bidirectional manner across early childhood [34, 35]. For example, time spent in focussed literacy and numeracy learning activities provides the opportunity to extend and enhance self-regulatory capacities, particularly in attentional and cognitive control aspects. It is likely that had we had an earlier and multiple measures of both selfregulation and early concept comprehension, literacy, and numeracy, we would have established birdirectional and reciprocal associations across time. A second and related explanation is that the pre-academic assessment used here may have tapped children's visual-motor skills given it was a pencil and paper task requiring the writing of letters. While there was no visual-motor data available for children in this dataset, scores on the pre-academic test did correlate $(r=.40)$ with the fine motor variable in our model (single item of teacher report of fine motor competence). Recent research has suggested that visual-motor skills and cognitive self-regulation, as enabled by executive functions, co-develop in a bidirectional manner [35] and it may be that our findings are reflecting a small portion of this transactional process at this period of development. That is, children who scored more highly on the preacademic score may have done so due to higher visualmotor skills, which may themselves co-develop with and support self-regulatory growth.

Pre-school gross motor abilities were also significantly, albeit modestly, associated with children's self-regulation growth. This is consistent with suggestions of common mechanisms (i.e., executive functions) that are implicated in both self-regulation and motor learning [36-38], such that both show common areas of neural activation, are impaired after damage to neural regions for the other, and are often both impaired in cognitive disorders, such as ADHD and dyslexia. Indeed, tasks that are motor-demanding for young children, such as navigating uneven surfaces and/or obstacles, are more cognitively demanding and lead to more 
Table 4 Standardized coefficients for the predictors of selfregulation at 6-7 years controlling for prior self-regulation and covariates

\begin{tabular}{|c|c|c|}
\hline & $\beta$ & $95 \% \mathrm{Cl}$ \\
\hline \multicolumn{3}{|l|}{$\begin{array}{l}\text { Covariate associations with self-regulation at } \\
4-5 \text { years }\end{array}$} \\
\hline Female & $.50^{* *}$ & $.44-.57$ \\
\hline Age & .01 & $.04-.11$ \\
\hline Birthweight percentile & $.07^{* *}$ & $.03-.11$ \\
\hline Breastfed & -.15 & $-.29--.01$ \\
\hline Aboriginal Torres Strait Islander & $-.53^{* *}$ & $-.81--.26$ \\
\hline Non-English home language & .01 & $-.10-.11$ \\
\hline Maternal education level & $.13^{* *}$ & $.09-.17$ \\
\hline Household income & $.13^{* *}$ & $.08-.17$ \\
\hline Stability of self-regulation 4-5 years to $6-7$ years & $.54^{* *}$ & $.49-.59$ \\
\hline \multicolumn{3}{|l|}{$\begin{array}{l}\text { Predictors of self-regulation at 6-7 years } \\
\text { controlling for above }\end{array}$} \\
\hline \multicolumn{3}{|l|}{ Health } \\
\hline Physical health status & .02 & $-.03-.05$ \\
\hline High sugar drink intake & .02 & $-.01-.06$ \\
\hline Sleep problems & $-.08^{* *}$ & $-.13--.04$ \\
\hline \multicolumn{3}{|l|}{ Development } \\
\hline Vocabulary & .01 & $-.03-.06$ \\
\hline Gross motor & $.06^{* *}$ & $.02-.10$ \\
\hline Fine motor & -.05 & $-.10-.00$ \\
\hline Pre-academic skills & $.12^{* *}$ & $.09-.16$ \\
\hline \multicolumn{3}{|l|}{ Home environment } \\
\hline Maternal angry parenting & $-.10^{* *}$ & $-.15-.06$ \\
\hline Paternal angry parenting & $-.12^{* *}$ & $-.16--.07$ \\
\hline Maternal consistent parenting & -.01 & $-.04-.05$ \\
\hline Paternal consistent parenting & .02 & $-.02-.07$ \\
\hline Maternal mental health & -.01 & $-.06-.04$ \\
\hline Paternal mental health & .02 & $-.03-.06$ \\
\hline Shared book reading frequency & .03 & $-.01-.07$ \\
\hline Home learning activities & $.06^{*}$ & $.01-.10$ \\
\hline Financial hardship & $-.07^{* *}$ & $-.12--.02$ \\
\hline Argumentative parental relationships & -.03 & $-.07-.02$ \\
\hline Stressful life events & -.00 & $-.04-.04$ \\
\hline \multicolumn{3}{|l|}{ Education } \\
\hline Educator-child relationship & $.06^{*}$ & $.01-.11$ \\
\hline \multicolumn{3}{|l|}{ Time use } \\
\hline Extra-curricular sport & -.02 & $-.05-.02$ \\
\hline Extra-curricular music/dance & .02 & $-.01-.05$ \\
\hline Weekday TV hours & .04 & $.00-.08$ \\
\hline Weekday computer hours & .01 & $-.03-.05$ \\
\hline Physical activity & -.03 & $-.06-.00$ \\
\hline \multicolumn{3}{|l|}{ Neighbourhood } \\
\hline Liveability & -.01 & $-.05-.02$ \\
\hline Socio-economic index & .01 & $-.03-.04$ \\
\hline
\end{tabular}

cognitive errors than less cognitively demanding motor tasks [39]. As such, one possibility is that this finding is indicative of the concomitance between self-regulatory and motor skills. However, that gross motor skills were associated with change in self-regulation may additionally suggest that the acquisition of motor proficiency creates new learning opportunities [40] such as experiences that serve to foster self-regulation (e.g., increased mobility causing children to encounter rules associated with access, involvement in physically active shared play providing opportunities for impulse control and turn-taking, etc.) As such, gross motor skills may open a gateway to important self-regulationpromoting experiences and activities, whereas low levels of gross motor skills might consume much of the cognitive resource that otherwise could be directed toward these same activities.

Another factor that was modestly but significantly and uniquely related to self-regulation growth was sleep problems. This aligns with a large body of existing research that identifies sleep problems as a key contributor to daytime self-regulatory problems in young children both in the short [41] and long term [18, 42]. It is possible that behavioural sleep problems in young children reflect an underlying phenotype associated with regulatory problems $[43,44]$, and/or that early behavioural sleep problems initiate a developmental cascade that disrupts emotional and attentional development over time [15]. Either way, brief sleep interventions are known to be safe and effective in improving both sleep behaviours and daytime selfregulatory functioning in young children in both typicallydeveloping [45-47] and clinical populations $[48,49]$.

Our finding that angry parenting was associated with less growth in self-regulation for children echoes a range of prior studies that have linked aggressive, controlling parenting with poor self-regulation in children [50-54]. However, this study extends that work by including not only mothers' but also fathers' parenting, a rare inclusion. We suggest that angry parenting as measured here is indicative of dysregulated parenting, and potentially of overall emotional regulation skills of parents. Mechanisms through which this might limit self-regulatory growth in children include heritability pathways in terms of self-regulation capabilities [55], and socialisation pathways in which children learn about self-regulatory behaviours through modelling their parents' behaviours. It is also important to note that child-driven effects are possible, as reflected in prior studies that show dysregulation in young children is associated with increased parenting stress and more-negative parenting approaches [56, 57]. These bidirectional relationships between parenting and children's self-regulation, which are likely to establish mutual promotion/exacerbation processes over time, were not modelled in this study and should be the focus of future longitudinal work. 
A number of socioeconomic variables were associated with enhanced self-regulatory growth including higher household incomes, higher maternal education levels and living in households with lower levels of financial hardship. The experience of significant financial hardships such as those tapped here is likely associated with stressful home environments, which impact on children's physiology and neurodevelopment in ways that limit their capacity for selfregulation development [58, 59]. Indeed, early selfregulation has been identified as one of the foremost mechanisms through which early stressors and socioeconomic disadvantage can lead to poorer academic and wellbeing outcomes [60]. For these reasons, much of the prevention and intervention focus to date has been on children from disadvantaged backgrounds in an effort to address socio-economic gradients in achievement likely mediated through early self-regulatory capacity. Our findings suggest this focus is well-placed.

Marginal effects were also found for the association between educator-child relationships and the home learning environment, with self-regulatory change. The finding regarding importance of educator-child relationship in terms of children's early self-regulation development reflects other similar findings in both Australia [61] and Europe [62]. Positive student-teacher relationships likely matter because they set the context within which teachers can enact strategies particularly important for acquiring selfregulation during the preschool developmental period [63] including co-regulation, modelling and coaching [64]. Our findings regarding the home learning environment align with a prior American longitudinal study linking parental involvement in home learning activities with children's self-regulatory development [65].

\section{Limitations}

Although this study included a comprehensive array of predictors of self-regulation growth across a specific period in early childhood, there are a number of limitations related primarily to measurement. Most measures were broad and blunt instruments of their constructs. This reflects the nature of the population dataset, in which a broad spectrum of measures capturing child development and the environment were desired, rather than an in-depth measurement of any particular constructs. In addition, our self-regulation composite was only available at two time points in this dataset, meaning that more sophisticated growth curve modelling, which requires a minimum of three time points, could not be undertaken. It is also important to note that although we included a wide array of predictors, nearly $60 \%$ of the variance in our self-regulation composite at 6-7 years was still unexplained by the model. This suggests that even large-scale studies such as these are missing key ingredients related to self-regulatory growth. Our understandings could be enhanced through studies which capture potential variables that are not often measured, including chronic stress (e.g. cortisol), psychophysiological arousal and regulation, sensory processing, and more detailed understandings of the nature of home learning and early education and care activities. Finally, it is important to note that participants in this study were recruited in 2004. While it is anticipated that there has been limited change in most lifestyle factors investigated (e.g., parenting), new cohort studies are required to better understand the influence of more prominent societal change such as increased access and use of digital devices.

\section{Conclusion}

While we know that self-regulation is important for a broad range of longitudinal achievement and wellbeing outcomes, and that early childhood is a key window for self-regulatory growth, we have not yet been overly effective in intervention efforts. One reason for this might be that we need more holistic and evidence-informed theories and approaches to self-regulatory development, rather than a focus on single factors that appear predictive in isolation. We need more complex modelling of the interactions between these various factors and their association with self-regulation change (not just prediction at one time point). The findings of this study suggest a starting point for further detailed research that aims to achieve this.

\section{Abbreviations}

K cohort: Kindergarten cohort; LSAC: Longitudinal Study of Australian Children

Acknowledgements

Not applicable.

\section{Authors' contributions}

KW co-conceptualised the study, undertook all final analyses and was a major contributor to the writing of the paper. SH created the key outcome composite variables for self-regulation, co-conceptualised the study and was a major contributor to the writing of the paper. All authors have read and approved the manuscript.

\section{Funding}

There was no funding attached to this study.

\section{Availability of data and materials}

The dataset analysed for the current study is available from the Australian Data Archive https://dataverse.ada.edu.au/dataset.xhtml?persistentld=doi:1 $0.26193 /$ JOZW2U

\section{Ethics approval and consent to participate}

Ethics approval for participants in the Longitudinal Study of Australia Children was approved by the Human Research Ethics Committee of the Australian Institute of Family Studies. 


\section{Competing interests}

The authors declare that they have no competing interests.

\section{Author details}

${ }^{1}$ School of Early Childhood \& Inclusive Education, Faculty of Education, Queensland University of Technology, QUT, Level 4 E Block, Victoria Park Road, Kelvin Grove, QLD 4059, Australia. ${ }^{2}$ Early Start, School of Education, Faculty of Social Sciences, University of Wollongong, Wollongong, Australia.

\section{Received: 5 March 2020 Accepted: 7 May 2020}

\section{Published online: 18 May 2020}

\section{References}

1. McClelland MM, Acock AC, Piccinin A, Rhea SA, Stallings MC. Relations between preschool attention span-persistence and age 25 educational outcomes. Early Child Res Q. 2013;28:314-24.

2. Howard SJ, Williams KE. Early self-regulation, early self-regulatory change, and their longitudinal relation sto adolescents' academic, health, and mental well-being outcomes. J Dev Behav Pediatrics. 2018:39:489-96.

3. Moffitt TE, Arseneault L, Belsky J, Dickson N, Hancox R, Harington $\mathrm{H}$, et al. A gradient of childhood self-control predicts health, wealth, and public safety. Proc Natl Acad Sci. 2011;108(7):2693-8.

4. Williams KE, Nicholson JM, Walker S, Berthelsen D. Early childhood profiles of sleep problems and self-regulation predict later school adjustment. Br J Educ Psychol. 2016;86(2):331-50.

5. Sawyer ACP, Miller-Lewis LR, Searle AK, Sawyer MG, Lynch JW. Is greater improvement in early self-regulation associated with fewer behavioral problems later in childhood? Dev Psychol. 2015;51(12):1740-55.

6. Slutske WS, Moffitt TE, Poulton R, Caspi A. Undercontrolled temperament at age 3 predicts disordered gambling at age 32: a longitudinal study of a complete birth cohort. Psychol Sci. 2012;23(5):510-6.

7. Sawyer ACP, Chittleborough CR, Mittinty MN, Miller-Lewis LR, Sawyer MG, Sullivan T, et al. Are trajectories of self-regulation abilities from ages 2-3 to 6-7 associated with academic achievement in the early school years? Child: Care Health Dev. 2014:41:744-54.

8. Takacs ZK, Kassai R. The efficacy of different interventions to foster children's executive function skills: a series of meta-analyses. Psychol Bull. 2019;145(7):653-97.

9. Diamond A. Activities and programs that improve children's executive functions. Curr Dir Psychol Sci. 2012;21(5):335-41.

10. Jacob R, Parkinson J. The potential for school-based interventions that target executive function to improve academic achievement: a review. Rev Educ Res. 2015;85(4):512-52.

11. Baker CE, Cameron CE, Rimm-Kaufman SE, Grissmer D. Family and sociodemographic predictors of school readiness among African American boys in kindergarten. Early Educ Dev. 2012;23(6):833-54.

12. Hindman AH, Morrison FJ. Differential contributions of three parenting dimensions to preschool literacy and social skills in a middle-income sample. Merrill-Palmer Q. 2012:58(2):191-223.

13. Kim H, Byers Al, Cameron CE, Brock LL, Cottone EA, Grissmer DW. Unique contributions of attentional control and visuomotor integration on concurrent teacher-reported classroom functioning in early elementary students. Early Child Res Q. 2016:36:379-90.

14. Hanno E, Surrain $\mathrm{S}$. The direct and indirect relations between self-regulation and language development among monolinguals and dual language learners. Clin Child Fam Psychol Rev. 2019;22:75-89.

15. Williams KE, Berthelsen D, Walker S, Nicholson JM. A developmental cascade model of behavioral sleep problems and emotional and attentional selfregulation across early childhood. Behav Sleep Med. 2017;15(1):1-21.

16. Soloff C, Lawrence D, Johnstone R. The Longitudinal Study of Australian Children LSAC Technical Paper 1: Sample design.: Australian Government Department of Family and Community Services; 2005.

17. Varni JW, Seid M, Rode CA. The PedsQL: measurement model for the pediatric quality of life inventory. Med Care. 1999;37(2):126-39.

18. Quach J, Nguyen CD, Williams KE, Sciberras E. Bidirectional associations between child sleep problems and internalizing and externalizing difficulties from preschool to early adolescence. JAMA Pediatr. 2018; 172(2):e174363.

19. Dunn LM, Dunn LM. Examiner's manual for the Peabody picture vocabulary test (3rd edn.). Circle Pines: American Guidance Service; 1997.

20. de Lemos M, Doig B. Who am I developmental assessment manual. Melbourne: ACER Press; 2000.
21. Australian Council for Educational Research. Who Am I Supplementary Information; 2007.

22. Zubrick SR, Lucas RE, Westrupp EM, Nicholson JM. Growing up in Australia: The Longitudinal Study of Australian Children (LSAC). LSAC Technical Paper No. 12. Parenting measures in the Longitudinal Study of Australian Children: construct validity and measurement quality, Waves 1 to 4. Canberra: Australian Government Department of Social Services; 2014.

23. Statistics Canada. National Longitudinal Survey of Children \& Youth Cycle 3 Survey Instruments 1998-99. Book 1 - Parent \& Child; 1999.

24. Furukawa TA, Kessler RC, Slade T, Andrews G. The performance of the K6 and K10 screening scales for psychological distress in the Australian National Survey of mental health and well-being. Psychol Med. 2003;33(2): $357-62$.

25. Hayes N, Berthelsen DC, Nicholson JM, Walker S. Trajectories of parental involvement in home learning activities across the early years: associations with socio-demographic characteristics and children's learning outcomes. Early Child Dev Care. 2018;188(10):1405-18.

26. Spencer N, Strazdins L. Socioeconomic disadvantage and onset of childhood chronic disabling conditions: a cohort study. Arch Dis Child. 2015;100:317-22.

27. Lewis AJ, Olsson CA. Early life stress and child temperament style as predictors of childhood anxiety and depressive symptoms: Findings from the Longitudinal Study of Australian Children. Depress Res Treat. 2011: 296026.

28. Pianta R. Student-teacher relationship scale. Psychological Assessment Resources: Odessa; 2001

29. Gialamas A, Sawyer ACP, Mittinty MN, Zubrick SR, Sawyer MG, Lynch J. Quality of childcare influences children's attentiveness and emotional regulation at school entry. J Pediatr. 2014;165:813-9.

30. Australian Bureau of Statistics. Socio-Economic Indexes for Areas Canberra, Australia: Australian Bureau of Statistics; 2018 [updated 27 March 2018. Available from: https:/www.abs.gov.au/websitedbs/censushome.nsf/home/seifa.

31. Enders C. Applied missing data analysis. New York: Guildford Press; 2010

32. Soloff C, Lawrence D, Misson S, Johnstone R. The Longitudinal Study of Australian Children LSAC Technical paper No.3: Wave 1 weighting and nonresponse; 2006.

33. Robson DA, Allen MS, Howard SJ. Self-regulation in childhood as a predictor of future outcomes: A meta-analytic review. Psychological Bulletin. 2020; Epub Jan 6.

34. Fuhs MW, Nesbitt KT, Farran DC, Dong N. Longitudinal associations between executive functioning and academic skills across content areas. Dev Psychol. 2014;50(6):1698-709.

35. McClelland MM, Cameron CE. Developing together: the role of executive function and motor skills in children's academic lives. Early Childhood Res Quarterl. 2019:46:143-51.

36. Cook CJ, Howard SJ, Scerif G, Twine R, Kahn K, Norris SA, et al. Associations of physical activity and gross motor skills with executive function in preschool children from low-income south african settings. Dev Sci. 2019;22:e1 2820.

37. Diamond A. Close interrelation of motor development and cognitive development and of the cerebellum and prefrontal cortex. Child Dev. 2000; 71(1):44-56

38. Oberer N, Gashaj V, Roebers CM. Motor skills in kindergarten: internal structure, cognitive correlates and relationships to background variables. Hum Mov Sci. 2017;52:170-80.

39. Berger SE. Locomotor expertise predicts infants' perseverative errors. Dev Psychol. 2010;46(2):326-36.

40. Campos JJ, Kermoian R, Zumbahlen MR. Socioemotional transformations in the family system following infant crawling onset. In: Eisenberg N, Fabes RA, editors. Emotion and its regulation in early development. New directions for child development, No. 55: The Jossey-Bass education series; ISSN: 01952269 (Print). San Francisco: Jossey-Bass; 1992. p. 25-40

41. Wilson KE, Lumeng JC, Kaciroti N, Chen SY-P, LeBourgeois MK, Chervin $\mathrm{RD}$, et al. Sleep hygiene practices and bedtime resistance in lowincome preschoolers: does temperament matter? Behav Sleep Med. 2015;13(5):412-23.

42. Van den Bergh BRH, Mulder EJH. Fetal sleep organization: a biological precursor of self-regulation in childhood and adolescence? Biol Psychol. 2012;89(3):584-90.

43. Melegari MG, Sette S, Vittori E, Mallia L, Devoto A, Lucidi F, et al. Relations Between Sleep and Temperament in Preschool Children With ADHD. Journal Of Attention Disorders. 2018;24(4):535-44. 
44. Williams KE, Sciberras E. Sleep and self-regulation from birth to 7 years: a retrospective study of children with and without attentiondeficit hyperactivity disorder at 8 to 9 years. J Dev Behav Pediatr. 2016:37(5):385-94.

45. Price AMH, Wake M, Ukoumunne OC, Hiscock H. Five-year follow-up of harms and benefits of behavioral infant sleep intervention: randomized trial. Pediatrics. 2012;130(4):643-51.

46. Price AMH, Wake M, Ukoumunne OC, Hiscock H. Outcomes at six years of age for children with infant sleep problems: longitudinal community-based study. Sleep Med. 2012;13(8):991-8.

47. Quach J, Hiscock H, Ukoumunne OC, Wake M. A brief sleep intervention improves outcomes in the school entry year: a randomized controlled trial. Pediatrics. 2011;128(4):692-701.

48. Papadopoulos N, Sciberras E, Hiscock H, Mulraney M, McGillivray J, Rinehart $\mathrm{N}$. The efficacy of a brief behavioral sleep intervention in school-aged children with $\mathrm{ADHD}$ and comorbid autism spectrum disorder. J Atten Disord. 2019;23(4):341-50.

49. Hiscock H, Sciberras E, Mensah FK, Gerner B, Efron D, Khano S, et al. Impact of a behavioural sleep intervention on symptoms and sleep in children with attention deficit hyperactivity disorder, and parental mental health: randomised controlled trial. BMJ. 2015;350(h68):1-14. https://www.bmj.com/ content/350/bmj.h68.

50. Graziano PA, Calkins SD, Keane SP. Sustained attention development during the toddlerhood to preschool period: associations with toddlers' emotion regulation strategies and maternal behaviour. Infant Child Dev. 2011;20(6):389-408.

51. Nelson JA, O'Brien M, Calkins SD, Leerkes EM, Marcovitch S, Blankson AN. Maternal expressive style and children's emotional development. Infant Child Dev. 2012;21(3):267-86.

52. Olson SL, Lopez-Duran N, Lunkenheimer ES, Chang H, Sameroff AJ. Individual differences in the development of early peer aggression: integrating contributions of self-regulation, theory of mind, and parenting. Dev Psychopathol. 2011;23(1):253-66.

53. Spinrad TL, Eisenberg N, Silva KM, Eggum ND, Reiser M, Edwards A, et al. Longitudinal relations among maternal behaviors, effortful control and young children's committed compliance. Dev Psychol. 2012;48(2):552-66.

54. Williams KE, Berthelsen D. The development of prosocial behaviour in early childhood: contributions of early parenting and self-regulation. Int J Early Childhood. 2017:49(1):73-94.

55. Scott BG, Lemery-Chalfant K, Clifford S, Tein J-Y, Stoll R, Goldsmith HH. A twin factor mixture modeling approach to childhood temperament: differential heritability. Child Dev. 2016;87(6):1940-55.

56. Barnes JC, Boutwell BB, Beaver KM, Gibson CL. Analyzing the Origins of Childhood Externalizing Behavioral Problems. Dev Psychol. 2013;49(12):2272-84.

57. Healey DM, Flory JD, Miller CJ, Halperin JM. Maternal positive parenting style is associated with better functioning in hyperactive/inattentive preschool children. Infant Child Dev. 2011;20(2):148-61.

58. Blair C, Raver C, Granger D, Mills-Koonce R, Hibel LC, Investigators FLP. Allostasis and allostatic load in the context of poverty in early childhood. Dev Psychopathol. 2011;23(3):845-57.

59. Farah M. The neuroscience of socioeconomic status: correlates, causes, and consequences. Neuron. 2017:96(1):56-71.

60. Blair C, Raver CC. School readiness and self-regulation: a developmental psychobiological approach. Annu Rev Psychol. 2015;66:711-31.

61. Gialamas A, Alyssa CP, Sawyer A, Mittinty MN, Zubrick SR, Sawyer MG, et al. Quality of childcare influences children's attentiveness and emotional regulation at school entry. J Pedatrics. 2014;165(4):813-9.

62. Cadima J, Verschueren K, Leal T, Guedes C. Classroom interactions, dyadic teacher-child relationships, and self-regulation in socially disadvantaged young children. J Abnorm Child Psychol. 2016;44(1):7-17.

63. Kopp CB. Antecedents of self-regulation: a developmental perspective. Dev Psychol. 1982;18(2):199-214.

64. Silkenbeumer JR, Schiller E-M, Kärtner J. Co- and self-regulation of emotions in the preschool setting. Early Child Res Q. 2018;44:72-81.

65. Baker CE. Fathers' and mothers' home literacy involvement and children's cognitive and social emotional development: implications for family literacy programs. Appl Dev Sci. 2013;17(4):184-97.

\section{Publisher's Note}

Springer Nature remains neutral with regard to jurisdictional claims in published maps and institutional affiliations.

Ready to submit your research? Choose BMC and benefit from:

- fast, convenient online submission

- thorough peer review by experienced researchers in your field

- rapid publication on acceptance

- support for research data, including large and complex data types

- gold Open Access which fosters wider collaboration and increased citations

- maximum visibility for your research: over $100 \mathrm{M}$ website views per year

At BMC, research is always in progress.

Learn more biomedcentral.com/submissions 